\title{
Huertos botánicos: alternativa mayangna contra la pérdida de valores por el desuso de medicina tradicional
}

\author{
Ethelmina Benjamín Rener
}

Un porcentaje considerable de los habitantes de las comunidades de Sakalwas, Padriwas y Nazaret, en el Territorio Mayangna Sauni As, están olvidándose de las prácticas tradicionales, como solución de sus problemas de salud, y están utilizando la medicina occidental para resolverlos. Esto implica la pérdida de los conocimientos sobre la medicina ancestral y el consiguiente deterioro de nuestra identidad la cual está íntimamente ligada a esta práctica ancestral.

\section{Causas principales por las cuales ha} decrecido el uso de plantas medicinales

Las plantas medicinales, desde los tiempos de nuestros abuelos hasta la fecha, no han perdido el poder curativo que tenían cuando los sukias mayangnas no cobraban a las personas enfermas por las curaciones que hacían. Sin embargo, en la actualidad, curanderos externos que no tienen piedad de los pobres enfermos están cobrando un precio exagerado por cualquier pequeña curación. Este mal ejemplo ha sido seguido por algunos de nuestros sukias y es uno de los factores negativos que han hecho disminuir el uso de la medicina tradicional en nuestras comunidades.

El otro factor dañino es el tiempo prolongado de abstinencia de ciertos alimentos que los curanderos recetan al paciente luego de la curación. Un paciente curado tiene prohibido por un tiempo definido por el sukia- comer carne, pescado y condimentos, dependiendo del tipo de enfermedad. Según la afección de la cual fue curado puede comer únicamente ciertos alimentos. Esto está en dependencia del criterio del sukia que, en el marco de la cosmovisión mayangna, manifiesta que todos los animales, acuáticos, terrestre y aves, tienen sus espíritus dueños (Liwa Pihni, Liwa Sâni, Duhindu, Asangdaniwan, Sau Daniwan) quienes son los causantes de las diferentes enfermedades. Por eso, los pacientes curados que no cumplen con estas orientaciones se exponen a que la enfermedad retorne.

\section{Propuestas para el rescate de la medicina tradicional y preservación del uso de plantas medicinales}

Los líderes y ancianos: Morales Molina (wihta), Alejandro Davis M. (síndico) y Rosa Elena Davis (anciana), de la comunidad de Padriwas, propusieron formar una organización de curanderos y curanderas del Territorio, para elaborar un proyecto de recolección de plantas medicinales -haciendo un huerto ( 25 plantas)- en cada comunidad mencionada en este estudio; realizar charlas (los curanderos) con los estudiantes de distintas modalidades en cada comunidad, para que conozcan las plantas y qué enfermedades pueden tratar; y escribir un libro de recetas de tratamiento de las plantas por enfermedad. 
Recetario mayangna de algunas plantas medicinales y sus usos

\begin{tabular}{|c|c|}
\hline Plantas medicinales & Enfermedades \\
\hline Wiluh sasnin, was sarap. & $\begin{array}{l}\text { Afecciones causadas por el espíritu de las } \\
\text { aguas (Sirena Blanca). }\end{array}$ \\
\hline Dibirtin bikisni, baram. & Diarreas con sangre. \\
\hline $\begin{array}{l}\text { Baram basni, mankru basni, tayuyu basni, } \\
\text { sumah basni. }\end{array}$ & Ataques causados por la Sirena Blanca. \\
\hline $\begin{array}{l}\text { Iskalastah sangni, dì birhtin bikisni, ubitna } \\
\text { bikisni. was burimak. }\end{array}$ & Infecciones urinarias. \\
\hline Kisauri, kuma sirpi, kiki panan. & Dolor de cabeza y gripe. \\
\hline Kauhmak sinika. tî basni, rikni. & $\begin{array}{l}\text { Para contrarrestar enfermedades } \\
\text { producidas por el espíritu de la Sirena. }\end{array}$ \\
\hline $\begin{array}{l}\text { Baram, kuma sirpi, kisauri, aras kasnin, } \\
\text { di birhtin. }\end{array}$ & $\begin{array}{l}\text { Problemas respiratorios producidos por el } \\
\text { espíritu Win Daniwan. }\end{array}$ \\
\hline Pulu sasang, kungtitir, kisauri. & $\begin{array}{l}\text { Aire en el estómago y diarrea causados el } \\
\text { espíritu de los muertos (Dauna Daniwan). }\end{array}$ \\
\hline Kisauri, awal basni, pan muhul. & $\begin{array}{l}\text { Para curar enfermedades causadas por el } \\
\text { espíritu del duende. }\end{array}$ \\
\hline
\end{tabular}

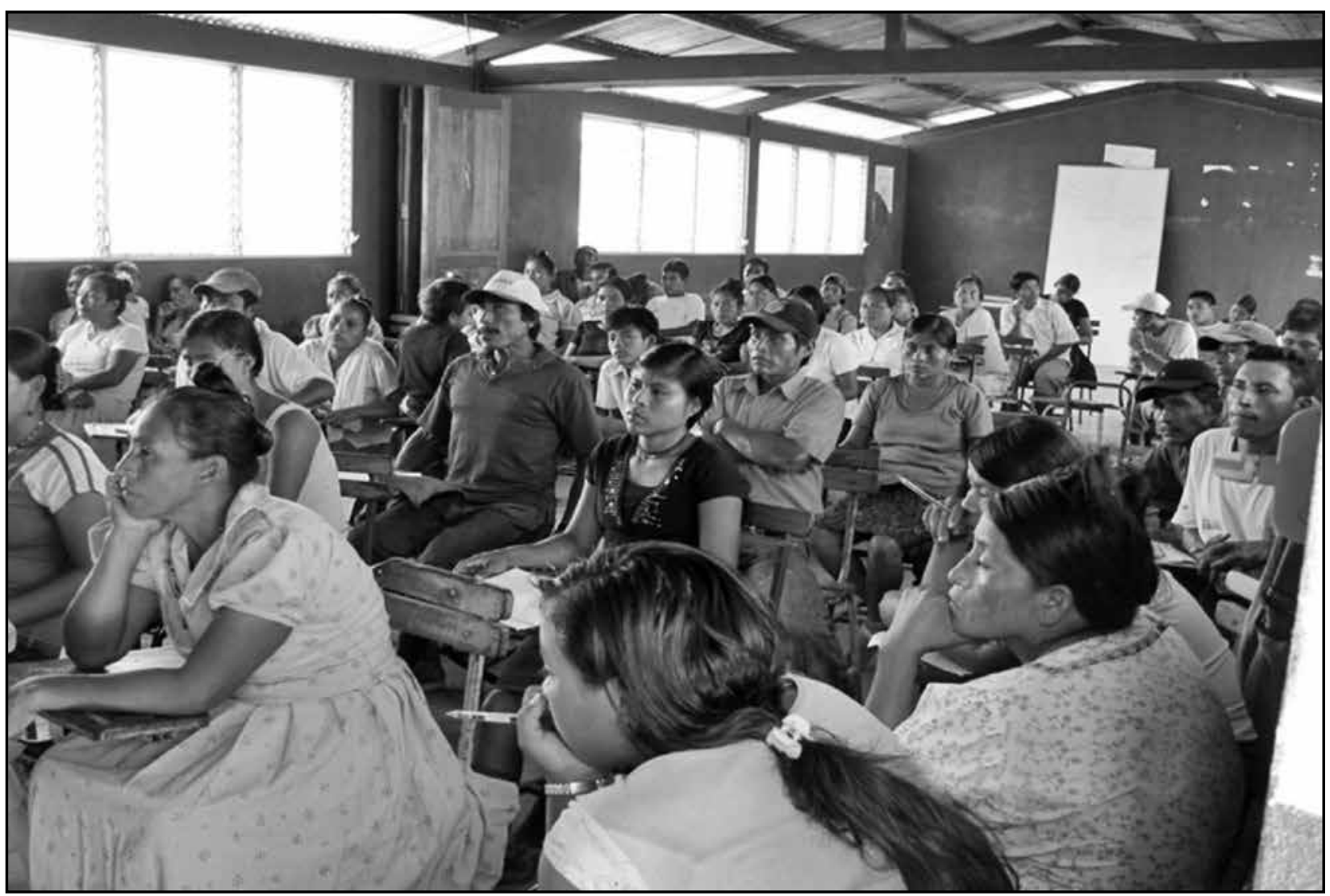

Indigenas asistentes a una reunión sobre huertos medicinales en el Territorio Mayangna Sauni As. 


\section{Conclusiones y recomendaciones}

Los objetivos de este proyecto de investigación se cumplieron todos, con excepción del establecimiento de los huertos botánicos de plantas medicinales en cada una de las tres comunidades, puesto que esto se cumplió parcialmente: sólo se pudo establecer el huerto de Sakalwas. Este objetivo era muy importante para cada una de las comunidades contempladas en el proyecto, porque estos huertos botánicos tienen la finalidad de responder a las emergencias de salud en las comunidades, ya que han sucedido casos en comunidades que, en altas horas de la noche, o en cualquier hora, inesperadamente, una persona es afectada por picadura de culebra u otra enfermedad como kalbubulna yamahni, que no se puede atender inmediatamente por falta de la planta medicinal, y muchos mueren porque el curandero no tiene cerca la plantas medicinales para el tratamiento. En la actualidad, los huertos en las comunidades de Nazaret y Padriwas están en proceso de establecerse.

\section{Nombres y apellidos de portadores consultados}

René Doblón, Filomena Guevara, Maura Pantin, Alberto Zeledón, Samuel Charles, Nicolás Zeledón, Jaime Lakwood, Francisco Molina, Herminia Molina, JesúsDavis, Morales Molina, Alejandro Davis, Rosa Elena Davis, Conrado Robins, Rosily lino Awabak, Ronaldo Blandon, Yosilina Davis, Tino Sebastián, Nicasio Davis, Nolberto Serapio, Richaida Erants, Cristóbal Hernández, Carmelo Indalecio. 